\title{
Article
}

\section{Gastric Cancer and the Daily Intake of the Major Dish Groups Contributing to Sodium Intake: A Case-Control Study in Korea}

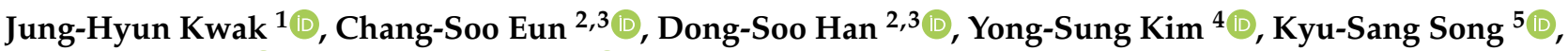 \\ Bo-Youl Choi ${ }^{6, *}$ (1) and Hyun-Ja Kim ${ }^{1, *}$ (1)
}

1 Department of Food and Nutrition, Gangneung-Wonju National University College of Life Science, 7 Jukheon-gil, Gangneung-si, Gangwon-do 25457, Korea; hyun4615@hanmail.net

2 Department of Internal Medicine, Hanyang University College of Medicine, 222 Wangsimni-ro, Seongdong-gu, Seoul 04763, Korea; cseun@hanyang.ac.kr (C.-S.E.); hands@hanyang.ac.kr (D.-S.H.)

3 Division of Gastroenterology, Department of Internal Medicine, Hanyang University Guri Hospital, 153 Gyeongchun-ro, Guri-si, Gyeonggi-do 11923, Korea

4 Funtional Genomics Institute, PDXen Biosystems Co., ETRI Convergence Commercialization Center, 218 Gajeong-ro, Yuseong-gu, Daejeon 34129, Korea; yskakim@gmail.com

5 Department of Pathology, Chungnam National University College of Medicine, 99 Daehak-ro, Yuseong-gu, Daejeon 34134, Korea; qsong@cnu.ac.kr

6 Department of Preventive Medicine, Hanyang University College of Medicine, 222 Wangsimni-ro, Seongdong-gu, Seoul 04763, Korea

* Correspondence: bychoi@hanyang.ac.kr (B.-Y.C.); wisekim@gwnu.ac.kr (H.-J.K.); Tel.: +82-2-2220-0662 (B.-Y.C.); +82-33-640-2967 (H.-J.K.); Fax: +82-2-2293-0660 (B.-Y.C.); +82-33-640-2330 (H.-J.K.)

Citation: Kwak, J.-H.; Eun, C.-S.; Han, D.-S.; Kim, Y.-S.; Song, K.-S.; Choi, B.-Y.; Kim, H.-J. Gastric Cancer and the Daily Intake of the Major Dish Groups Contributing to Sodium Intake: A Case-Control Study in Korea. Nutrients 2021, 13, 1365. https://doi.org/10.3390/nu13041365

Academic Editor: Edith Lahner

Received: 31 March 2021

Accepted: 16 April 2021

Published: 19 April 2021

Publisher's Note: MDPI stays neutral with regard to jurisdictional claims in published maps and institutional affiliations.

Copyright: (c) 2021 by the authors. Licensee MDPI, Basel, Switzerland. This article is an open access article distributed under the terms and conditions of the Creative Commons Attribution (CC BY) license (https:// creativecommons.org/licenses/by/ $4.0 /)$.
Abstract: Studies on the association between gastric cancer (GC) and the intake of soup-based dish groups (noodles and dumplings, soups, and stews), which are sodium-contributing foods, in Korea are insufficient, and the results of studies on the intake of pickled vegetables such as kimchi are inconsistent. This study aimed to determine the association between the incidence of GC and the daily intake of high-sodium dish groups (noodles and dumplings, soups, stews, and pickled vegetables) and whether these associations differ depending on behavioral risk factors for GC. In this case-control study, subjects aged 20-79 years were recruited from two hospitals between December 2002 and September 2006. A total of 440 cases and 485 controls were recruited, of which 307 pairs were matched and included for the analysis. In our results, a higher intake of noodles and dumplings was associated with a significantly increased incidence of GC. In the participants who consumed past or current alcohol, a higher intake of noodles and dumplings was associated with a significantly increased incidence of GC. Our results suggest that efforts to reduce the daily sodium intake from noodles and dumplings are needed to prevent and reduce the incidence of GC.

Keywords: gastric cancer; high-sodium dish groups; case-control study; sodium intake; smoking; alcohol drinking

\section{Introduction}

Based on GLOBOCAN 2020 data, gastric cancer (GC) is the fifth most common cancer and fourth for mortality globally, with an estimated 769,000 deaths in 2020 [1]. In particular, Korea has the highest incidence of GC [2]. According to Statistics Korea, the estimated crude incidence of gastric cancer (GC) was 57.1/100,000 persons in 2018, which was still higher than that of other cancers such as lung and liver cancer [3].

Recently, a systematic review reported the following as risk factors for GC: diet, lifestyle, genetic predisposition, family history, treatment and medical conditions, and Helicobacter pylori (H. pylori) infections [4]. The World Cancer Research Fund International (2018) reported that a higher consumption of foods preserved by salting may be a cause of GC [5]. In addition, several studies have reported that a high intake of salty foods or salts 
increases the risk of GC [6-10], and experimental studies support these findings [6,11]. On the other hand, our previous study and others found no association between salty food [12] or salt $[13,14]$ and GC. Some salty foods, such as fermented foods, contain antioxidant nutrients that are beneficial to health [15], and each study categorized salty foods slightly differently, which may have contributed to the inconsistency in the results $[7,8,10,12]$. In addition, it is difficult to measure an individual's exact sodium intake due to inaccuracies during measurement using dietary questionnaires.

According to Korea Health Statistics 2019, the daily intake of sodium is $3512.3 \mathrm{mg}$ (aged $\geq 19$ years) [16], which is more than twice the adequate intake $(1500 \mathrm{mg})$ as set in the 2020 Dietary Reference Intakes for Koreans [17]. The Korea National Health and Nutrition Examination Survey (KNHANES) VI (2013-2015) (aged $\geq 6$ years) presented noodles and dumplings, pickled vegetables, soups, and stews from 1st to 4th as major dish groups that contribute to sodium intake [18]. These data suggest that soup-based dish groups, such as noodles, soups, and stews, greatly contribute to sodium intake in Korea. The higher consumption of sodium by Koreans than inhabitants of other countries may be due to their soup-based diet as well as traditional pickled foods [19,20]. However, studies on the association between GC and soup-based dish groups are insufficient [21], and the results of studies on pickled vegetables, such as kimchi, are inconsistent [12,22,23].

In addition, smoking and alcohol consumption are well-known behavioral risk factors for GC [5]. Additionally, these behavioral factors are associated with unhealthy dietary patterns [24]. Some studies have reported that smokers or alcohol drinkers prefer salty food [25], and they have a low intake of fruits and dairy products and a high intake of fast food [26]. Smoking and alcohol consumption can act as carcinogenic factors [27], but when they are combined with unhealthy dietary habits, their effect on GC incidence may be worse.

Therefore, the primary goal of the present study was to determine the association between the incidence of GC and the daily intake in major dish groups that contribute to sodium intake. The secondary goal of this study was to evaluate whether the behavioral risk factors of GC (i.e., smoking and alcohol consumption) influence the association between the incidence of GC and the daily intake of major dish groups that contribute to sodium intake.

\section{Materials and Methods}

\subsection{Study Population}

Subjects aged 20-79 years were recruited from the Chungnam University Hospital and Hanyang University Guri Hospital between December 2002 and September 2006. Due to the slight change in the questionnaire items during the study period, the subjects were recruited in the following stages: 1st (December 2002 to August 2003) and 2nd (October 2003 and September 2006) stages. GC was histologically diagnosed based on the World Health Organization classification of tumors of the digestive system, as follows [28]: a gastroscopy was performed by a gastroenterologist and the final diagnosis of GC was confirmed by a pathologist through a biopsy. The control group comprised those who visited the same hospital during the same period and did not have any gastric problems. A total of 440 cases and 485 controls were recruited, of which 316 pairs were matched at a ratio of 1:1 by hospital, age within 5 years, sex, and study admission period within 1 year. Among the 316 pairs, the pairs with daily energy intakes of $<500 \mathrm{kcal}$ (five cases) or $>5000 \mathrm{kcal}$ (one case and two controls) and those with missing information on the intake of noodles and dumplings (one case) were excluded. Finally, 307 pairs (124 pairs for Chungnam University Hospital; 183 pairs for Hanyang University Guri Hospital) were included for this analysis. All participants provided written informed consent, and the study protocol was approved by the Institutional Review Board of Hanyang University Medical Center (IRB no. 2003-4). 


\subsection{Data Collection}

The questionnaire included questions on sociodemographic characteristics (i.e., sex, age, education level, etc.), behavioral factors (i.e., smoking and alcohol consumption), disease status, family history, and dietary habits. Height and weight were collected from the medical records and questionnaires. Body mass index (BMI) was computed as weight in kilograms divided by height in meters squared $\left(\mathrm{kg} / \mathrm{m}^{2}\right)$. We grouped the participants into four based on their BMI: "obese", $\geq 25 \mathrm{~kg} / \mathrm{m}^{2}$; "overweight", $23.0-24.99 \mathrm{~kg} / \mathrm{m}^{2}$; "normal weight", $18.5-22.99 \mathrm{~kg} / \mathrm{m}^{2}$; and "underweight", $\leq 18.49 \mathrm{~kg} / \mathrm{m}^{2}$. H. pylori infection was tested with the Campylobacter-like organism (CLO) test kit (Product no: 60480; KimberlyClark/Ballard Medical Products, Draper, UT, USA), a rapid urea degradation test. This test was performed when tissue collection was possible.

\subsection{Dietary Data}

The data on dietary factors were collected using a quantitative food frequency questionnaire (FFQ). The FFQs used for the 1st and 2nd stages had slightly different survey items and methods. For the first stage, the FFQ assessed 103 food or dish items, with an intake period (1-12 months) of 1 year, frequency of food consumption per month, week, or day, and average serving size. For the second stage, the FFQ comprised 116 food or dish items, frequency of food consumption with nine categories ("never or less than once a month", "1-3 times a month", "1 time a week", "2-4 times a week", "5-6 times a week", "once a day", " $2-3$ times a day", " $4-5$ times a day", and " $\geq 6$ times a day"), and average serving size. Therefore, we extracted the common food items for the first stage based on the second stage. After that, the food intake or nutrient intake was calculated for each of the stages, divided into three quartiles, and merged. This was converted into daily intake by considering the intake period and frequency, and the intake of each of the investigated foods. All questionnaires were administered by a well-trained interviewer and investigated the frequency and amount of food consumed during 12 months of 3 years before the date of the interview to assess remote dietary intake. The total energy intake for each food was estimated using the Korean Foods and Nutrients Database [29]. The dish groups with high sodium content were used as the four major dish groups (noodles and dumplings, pickled vegetables, soups, and stews) that contribute to the sodium intake of Koreans based on the 6th KNHANES data as follows [18]. First, noodles and dumplings were part of eight dishes, as follows: 1 . Noodles, banquet noodles (janchi-guksu), cold noodles (naengmyeon), and noodles in cold soybean soup (kong-guksu); 2. spicy mixed noodles, spicy noodles (bibim-guksu), spicy cold chewy noodles (jjolmyeon), and cold noodles with spicy dressing (bibim-naengmyeon); 3. instant noodles (ramen); 4 . noodles with black bean sauce (jajangmyeon); 5 . Chinese-style noodles with vegetables and seafood (jjamppong); 6. hand-pulled dough soup (sujebi) and chopped noodles (kal-guksu); 7. dumplings and dumpling soups; and 8. sliced rice cake soup (tteok-guk). Second, pickled vegetables comprised seven dishes, as follows: 1 . Chinese cabbage kimchi (baechu-kimchi); 2. radish kimchi; seasoned cubed radish roots (kkakduki), young summer radish kimchi (yeolmukimchi); 3. white kimchi (baek kimchi); 4. pickled radish (dongchimi); 5. sesame leaf kimchi; 6. cucumber kimchi; and 7. pickles (cucumber, red pepper, garlic, radish, etc.). Third, soups comprised nine dishes, as follows: 1 . beef soup; 2. beef bone soup (gomguk), ox bone soup (seolleong-tang), and short rib soup (galbi-tang); 3 spicy beef soup (yukgaejang) and hangover soup (haejangguk); 4 . chicken soup with ginseng (samgye-tang) and braised spicy chicken (dak-dori-tang); 5 . vegetable soybean paste soup; 6 . bean sprouts soup (kongnamul-guk) and bean sprout kimchi soup (kongnamul kimchi-guk); 7. cold wakame soup (miyeok naengguk) and seaweed soup (miyeok-guk); 8. dried cod soup (bugeoguk); and 9. invigorating soup (boshintang). Fourth, stews comprised four dishes, as follows: 1. kimchi stew (kimchi jjigae); 2 . soybean paste stew (doenjang jjigae) and fermented soybean paste stew (cheonggukjang jjigae); 3. pollack stew; and 4. other fish stews (mackerel, saury, blacktail, etc.). The daily intake of each dish was calculated by 
multiplying the frequency per day and intake amount and summing them to estimate the total daily intake of dish groups.

The dietary questionnaire included items on salty taste preference, with a 5-point Likert scale: (1) not favored at all; (2) slightly not favored; (3) no opinion; (4) slightly favored; and (5) strongly favored. The five responses on the salty taste preferences were classified into three categories: (1) not favored at all and slightly not favored; (2) no opinion; and (3) slightly favored and strongly favored.

\subsection{Statistical Analysis}

The statistical analysis was performed using the SAS 9.4 version (SAS Institute Inc., Cary, NC, USA). To compare the general characteristics of the cases and controls, the Student's $t$-test was used to analyze the continuous variables and the Chi-squared test was used for categorical variables. The continuous and categorical variables are presented as mean values \pm standard deviation and numbers (percentages), respectively. Since there was a slight difference between the FFQs for the first and second stages, the tertiles of each dish group were applied according to each stage. The odds ratios (OR) and $95 \%$ confidence intervals (CI) for the GC risk were calculated across the tertiles for each high-sodium dish group using logistic regression after controlling for known risk factors. The lowest tertile of each high-sodium dish group was used as a reference. To test for trends, the median values of each tertile category of the high-sodium dish groups were used as continuous variables. We analyzed the OR for GC according to the salty food preference of the participants who answered "no opinion" as the reference group. Model I was adjusted for age (as a continuous variable) and sex. Model II was further adjusted for BMI $(\leq 18.49,18.5-22.99$, 23.0-24.99, or $\geq 25$ ), education level ( $\leq$ elementary school, middle school, $\geq$ high school, or missing), family history (first-degree relatives) of GC (no, yes, or missing), smoking status (never, past, or current smoker), alcohol consumption (never, past, or current drinkers), total energy intake (as a continuous variable), and H. pylori infection (no, yes, or missing). In addition, we conducted a stratified analysis according to the GC risk factors (alcohol consumption or smoking status) for the fully adjusted model. During the stratification analysis, the stratified variables were excluded from the model. The current and past smokers were combined into the "ever smoked" group before analysis. Moreover, the current and past drinkers were combined into the "ever drank" group before analysis.

\section{Results}

\subsection{General Characteristics of Cases and Controls}

Table 1 describes the general characteristics of the 307 GC cases and 307 controls. The mean ages of the case and control groups were $56.9( \pm 12.0)$ years and $56.2( \pm 11.9)$ years, respectively. No difference was observed between the two groups based on sex and hospital visited due to the matching selection. In addition, no difference was observed between the cases and controls based on alcohol consumption, smoking status, education levels, and family history of GC. The case group had a lower prevalence of obesity $(22.2 \%)$ than the control group $(32.6 \%)(p=0.014)$. The control group had a higher proportion of participants with $H$. pylori infection $(45.6 \%)$ than the case group $(31.6 \%)(p<0.001)$. The case group consumed significantly more total energy than the control group $(p=0.002)$.

\subsection{Association between Behavioral GC Risk Factors and GC}

Table 2 shows the association between behavioral GC risk factors and the incidence of GC. Alcohol consumption was not significantly associated with the incidence of GC based on models I and II (model I: OR $=1.00,95 \%$ CI $=0.67-1.49$, model II: OR $=2.09$, $95 \% \mathrm{CI}=0.76-5.73$ ). Regarding smoking status, model I showed that the participants who had ever smoked had a significantly higher incidence of GC than those who had never smoked $(\mathrm{OR}=1.73,95 \% \mathrm{CI}=1.06-2.84)$. However, model II did not show that this was statistically significant $(\mathrm{OR}=1.51,95 \% \mathrm{CI}=0.62-3.66)$. 
Table 1. Participant characteristics of gastric cancer cases and controls.

\begin{tabular}{|c|c|c|c|}
\hline Characteristics & Cases $(n=307)$ & Controls $(n=307)$ & $p$-Values \\
\hline Age (year, mean $\pm S D$ ) & $56.9 \pm 12.0$ & $56.2 \pm 11.9$ & 0.450 \\
\hline \multicolumn{4}{|l|}{$\operatorname{Sex}(n, \%)$} \\
\hline Men & $206(67.1)$ & $206(67.1)$ & \multirow[t]{2}{*}{1.000} \\
\hline Women & $101(32.9)$ & $101(32.9)$ & \\
\hline \multicolumn{4}{|l|}{ Hospital $(n, \%)$} \\
\hline Chungnam University Hospital & $124(40.4)$ & $124(40.4)$ & \multirow[t]{2}{*}{1.000} \\
\hline Hanyang University Guri Hospital & $183(59.6)$ & $183(59.6)$ & \\
\hline \multicolumn{4}{|l|}{ Education $(n, \%)$} \\
\hline$\leq$ Elementary school & $90(29.3)$ & $92(30.0)$ & \multirow[t]{4}{*}{0.806} \\
\hline Middle school & $52(16.9)$ & $49(16.0)$ & \\
\hline$\geq$ High school & $136(44.3)$ & $143(46.6)$ & \\
\hline Missing & $29(9.5)$ & $23(7.5)$ & \\
\hline \multicolumn{4}{|l|}{ Family history of gastric cancer $(n, \%)^{\dagger}$} \\
\hline No & $244(79.5)$ & $259(84.4)$ & \multirow[t]{3}{*}{0.146} \\
\hline Yes & $46(15.0)$ & $30(9.8)$ & \\
\hline Missing & $17(5.5)$ & $18(5.9)$ & \\
\hline \multicolumn{4}{|l|}{ Body mass index $\left(\mathrm{kg} / \mathrm{m}^{2}\right)(n, \%)$} \\
\hline Underweight $(\leq 18.49)$ & $20(6.5)$ & $13(4.2)$ & \multirow[t]{5}{*}{0.014} \\
\hline Normal weight (18.5-22.99) & $134(43.7)$ & $102(33.2)$ & \\
\hline Overweight (23.0-24.99) & $61(19.9)$ & $69(22.5)$ & \\
\hline Obesity $(\geq 25)$ & $68(22.2)$ & $100(32.6)$ & \\
\hline Missing & $24(7.8)$ & $23(7.5)$ & \\
\hline \multicolumn{4}{|l|}{ H. pylori infection $(n, \%)$} \\
\hline No & $108(35.2)$ & $67(21.8)$ & \multirow[t]{3}{*}{$<0.001$} \\
\hline Yes & $97(31.6)$ & $140(45.6)$ & \\
\hline Missing & $102(33.2)$ & $100(32.6)$ & \\
\hline Total energy intake (kcal/day, mean $\pm \mathrm{SD}$ ) & $1870.8 \pm 741.5$ & $1700.9 \pm 619.6$ & 0.002 \\
\hline \multicolumn{4}{|l|}{ Alcohol consumption $(n, \%)$} \\
\hline Never & $104(33.9)$ & $103(33.6)$ & \multirow[t]{3}{*}{0.198} \\
\hline Former & $54(17.6)$ & $39(12.7)$ & \\
\hline Current & $149(48.5)$ & $165(53.8)$ & \\
\hline \multicolumn{4}{|l|}{ Smoking status $(n, \%)$} \\
\hline Never & $108(35.2)$ & $126(41.0)$ & \multirow[t]{4}{*}{0.343} \\
\hline Former & $93(30.3)$ & $89(29.0)$ & \\
\hline Current & $105(34.2)$ & $92(30.0)$ & \\
\hline Missing & $1(0.3)$ & $0(0)$ & \\
\hline
\end{tabular}

${ }^{+}$first-degree relative.

Table 2. Odds ratios of gastric cancer by alcohol consumption or smoking status.

\begin{tabular}{|c|c|c|c|c|c|}
\hline \multirow{2}{*}{ Variables } & \multirow{2}{*}{$\begin{array}{l}\text { No. of Cases } \\
\S / \text { Controls }\end{array}$} & \multicolumn{2}{|c|}{ Model I ${ }^{(1)}$} & \multicolumn{2}{|c|}{ Model II $^{(2)}$} \\
\hline & & OR & $(95 \% \mathrm{CI})$ & OR & $(95 \% \mathrm{CI})$ \\
\hline \multicolumn{6}{|c|}{ Alcohol consumption } \\
\hline Never & $104 / 103$ & 1.00 & Ref. & 1.00 & Ref. \\
\hline Ever & $203 / 204$ & 1.00 & $(0.67-1.49)$ & 2.09 & $(0.76-5.73)$ \\
\hline \multicolumn{6}{|l|}{ Smoking status } \\
\hline Never & $108 / 126$ & 1.00 & Ref. & 1.00 & Ref. \\
\hline Ever & $198 / 181$ & 1.73 & $(1.06-2.84)^{*}$ & 1.51 & $(0.62-3.66)$ \\
\hline
\end{tabular}

${ }^{*} p<0.05$ compared with reference group. OR, odds ratios; CIs, confidence intervals. ${ }^{(1)}$ Model I: adjusted for age and sex. ${ }^{(2)}$ Model II: model I + further adjusted for body mass index ( $\leq 18.49,18.5-22.99,23.0-24.99$, or $\geq 25)$, education level ( $\leq$ elementary school, middle school, $\geq$ high school, or missing), family history of gastric cancer (no, yes, or missing), smoking status (never, past, or current smokers), alcohol drinkers (non, past, or current drinkers), total energy intake (continuous), and H. pylori infection (no, yes, or missing). \& There was a missing value in smoking status (cases, $n=1$ ).

\subsection{Association between High-Sodium Dish Groups and GC}

Table 3 shows the association between the daily intake of high-sodium diet groups and the incidence of GC. For model I, the highest tertile of intakes of noodles and dumplings showed a significantly higher incidence of GC than the lowest tertile $(\mathrm{OR}=1.98,95 \% \mathrm{CI}=1.31-3.00$, 
$p$ for trend $=0.0005$ ). For model II, the fully adjusted model, the highest tertile of intakes of noodles and dumplings showed a significantly higher incidence of GC than the lowest tertile $(\mathrm{OR}=1.65,95 \% \mathrm{CI}=1.03-2.63, p$ for trend $=0.017)$. The daily intakes of soups and stews showed no significant differences related to the incidence of GC. In contrast, medium (the 2nd tertile) intake of pickled vegetables was associated with a tendency of a decrease in the incidence of GC $(\mathrm{OR}=0.67,95 \% \mathrm{CI}=0.44-1.02, p$ for trend $=0.288)$.

Table 3. Odds ratios of gastric cancer by high-sodium dish groups.

\begin{tabular}{|c|c|c|c|c|c|}
\hline \multirow{2}{*}{ Variables } & \multirow{2}{*}{$\begin{array}{c}\text { No. of } \\
\text { Cases/Controls }\end{array}$} & \multicolumn{2}{|c|}{ Model I (1) } & \multicolumn{2}{|c|}{ Model II (2) } \\
\hline & & OR & $(95 \% \mathrm{CI})$ & OR & $(95 \% \mathrm{CI})$ \\
\hline \multicolumn{6}{|c|}{ Noodles and dumplings } \\
\hline Tertile 1 & $86 / 120$ & 1.00 & Ref. & 1.00 & Ref. \\
\hline Tertile 2 & $106 / 97$ & 1.58 & $(1.06-2.34)^{*}$ & 1.31 & $(0.86-1.99)$ \\
\hline Tertile 3 & \multirow{2}{*}{\multicolumn{3}{|c|}{$<0.001^{(1.31-3.00)^{* x-4}}$}} & 1.65 & $(1.03-2.63)$ * \\
\hline$p$ for trend & & & & \multicolumn{2}{|c|}{0.017} \\
\hline \multicolumn{6}{|l|}{ Soups } \\
\hline Tertile 1 & $98 / 106$ & 1.00 & Ref. & 1.00 & Ref. \\
\hline Tertile 2 & $101 / 104$ & 1.09 & $(0.73-1.62)$ & 1.05 & $(0.69-1.61)$ \\
\hline Tertile 3 & $108 / 97$ & 1.26 & $(0.84-1.90)$ & 1.17 & $(0.75-1.82)$ \\
\hline$p$ for trend & & \multicolumn{2}{|c|}{0.559} & \multicolumn{2}{|c|}{0.927} \\
\hline \multicolumn{6}{|l|}{ Stews } \\
\hline Tertile 1 & $105 / 92$ & 1.00 & Ref. & 1.00 & Ref. \\
\hline Tertile 2 & $103 / 110$ & 0.82 & $(0.56-1.21)$ & 0.79 & $(0.52-1.20)$ \\
\hline Tertile 3 & $99 / 105$ & 0.83 & $(0.56-1.23)$ & 0.78 & $(0.51-1.19)$ \\
\hline$p$ for trend & \multicolumn{3}{|c|}{0.261} & \multicolumn{2}{|c|}{0.170} \\
\hline \multicolumn{6}{|l|}{ Pickled vegetables } \\
\hline Tertile 1 & $108 / 96$ & 1.00 & Ref. & 1.00 & Ref. \\
\hline Tertile 2 & $96 / 109$ & 0.78 & $(0.53-1.15)$ & 0.67 & $(0.44-1.02)^{\dagger}$ \\
\hline Tertile 3 & $103 / 102$ & 0.89 & $(0.60-1.32)$ & 0.80 & $(0.52-1.24)$ \\
\hline$p$ for trend & & \multicolumn{2}{|c|}{0.510} & \multicolumn{2}{|c|}{0.288} \\
\hline
\end{tabular}

${ }^{*} p<0.05,{ }^{* *} p<0.01,{ }^{\dagger} p<0.1$ compared with reference group. OR, odds ratios; CIs, confidence intervals. ${ }^{(1)}$ Model I: adjusted for age and sex. ${ }^{(2)}$ Model II: model I + further adjusted for body mass index ( $\leq 18.49,18.5-22.99,23.0-24.99$, or $\left.\geq 25\right)$, education level ( $\leq$ elementary school, middle school, $\geq$ high school, or missing), family history of gastric cancer (no, yes, or missing), smoking status (never, past, or current smokers), alcohol drinkers (non, past, or current drinkers), total energy intake (continuous), and H. pylori infection (no, yes, or missing).

\subsection{Association between the Daily Intake of Noodles and Dumplings and GC Stratified by Behavioral GC Risk Factors}

Table 4 shows the association between the daily intake of noodles and dumplings and the incidence of GC stratified by behavioral GC risk factors. When stratified by alcohol drinking status, the highest tertile of intakes of noodles and dumplings showed a significantly higher incidence of GC than the lowest tertile among participants who were past or current drinkers in the fully adjusted model $(\mathrm{OR}=2.00,95 \% \mathrm{CI}=1.12-3.56$, $p$ for trend $=0.017$ ), but this association was not significant among those who had never drunk. When stratified by smoking status, the highest tertile of the intakes of noodles and dumplings showed a tendency of an increase in the incidence of GC compared with the lowest tertile among the participants with past or current smokers in the fully adjusted model $(\mathrm{OR}=1.68,95 \% \mathrm{CI}=0.92-3.05, p$ for trend $=0.083)$. This association was not significant in the participants who had never smoked. 
Table 4. Association gastric cancer and intakes of noodles and dumplings according to alcohol consumption or smoking status.

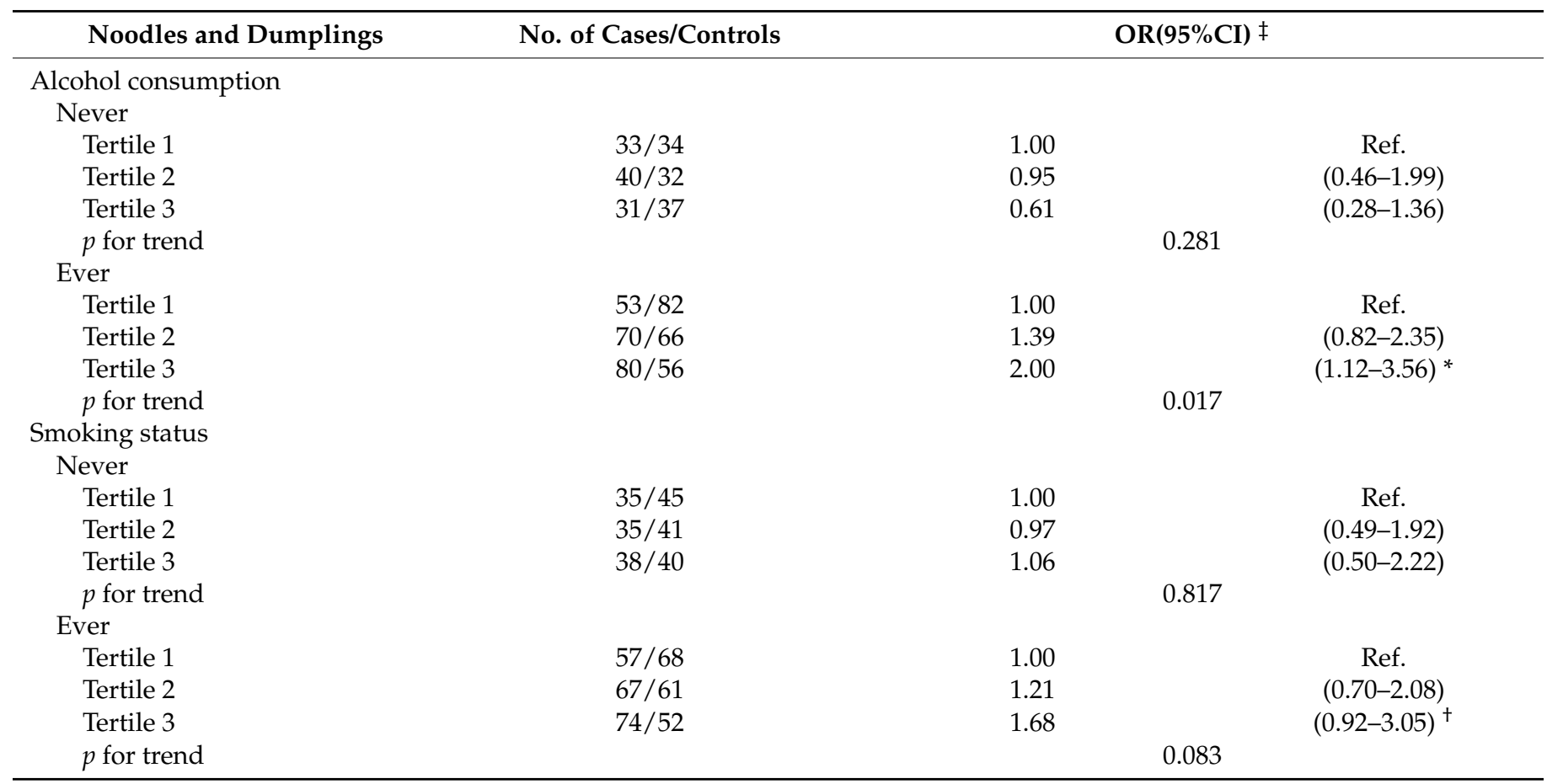

${ }^{*} p<0.05,{ }^{\dagger} p<0.1$ compared with reference group. OR, odds ratios; CIs, confidence intervals. ${ }^{\ddagger}$ adjusted for age, sex, body mass index ( $\leq 18.49,18.5-22.99,23.0-24.99$, or $\geq 25$ ), education level ( $\leq$ elementary school, middle school, $\geq$ high school, or missing), family history of gastric cancer (no, yes, or missing), smoking status (never, past, or current smokers), alcohol drinkers (non, past, or current drinkers), total energy intake (continuous), and H. pylori infection (no, yes, or missing). In stratification analysis, the stratified variable was excluded from the model.

\subsection{Association between the Preference of Salty Food and GC}

Table 5 shows the association between the preference for salty food and the incidence of GC. In model I, the participants who considered their salty food preference "slightly favored" and "strongly favored" showed a significantly increased incidence of GC than those had no opinion $(\mathrm{OR}=1.54,95 \% \mathrm{CI}=1.01-2.33, p$ for trend $=0.046)$. However, statistical significance was weakened in model II (OR $=1.51,95 \% \mathrm{CI}=0.97-2.36, p$ for trend $=0.153)$.

Table 5. Odds ratios of gastric cancer according to preference of salty food.

\begin{tabular}{|c|c|c|c|c|c|}
\hline \multirow{2}{*}{ Variables } & \multirow{2}{*}{$\begin{array}{l}\text { No. of Cases } \\
\S / \text { Controls }\end{array}$} & \multicolumn{2}{|c|}{ Model I (1) } & \multicolumn{2}{|c|}{ Model II (2) } \\
\hline & & OR & $95 \% \mathrm{CI}$ & OR & $95 \% \mathrm{CI}$ \\
\hline \multicolumn{6}{|l|}{ Preference of salty food } \\
\hline $\begin{array}{l}\text { Not favored at all } \\
\text { and slightly not favored }\end{array}$ & $87 / 102$ & 1.08 & $(0.69-1.70)$ & 1.17 & $(0.72-1.89)$ \\
\hline No opinion & $56 / 71$ & 1.00 & Ref. & 1.00 & Ref. \\
\hline $\begin{array}{l}\text { Slightly favored } \\
\text { and strongly favored }\end{array}$ & $163 / 134$ & 1.54 & $(1.01-2.33) *$ & 1.51 & $(0.97-2.36)^{\dagger}$ \\
\hline$p$ for trend & & \multicolumn{2}{|c|}{0.046} & \multicolumn{2}{|c|}{0.153} \\
\hline
\end{tabular}

${ }^{*} p<0.05,{ }^{\dagger} p<0.1$ compared with reference group. OR, odds ratios; CIs, confidence intervals. (1) Model I: adjusted for age and sex. (2) Model II: model I+ further adjusted for body mass index ( $\leq 18.49,18.5-22.99,23.0-24.99$, or $\geq 25)$, education level ( $\leq$ elementary school, middle school, $\geq$ high school, or missing), family history of gastric cancer (no, yes, or missing), smoking status (never, past, or current smokers), alcohol drinkers (non, past, or current drinkers), total energy intake (continuous), H. pylori infection (no, yes, or missing). ${ }^{\S}$ There was a missing value in the preference for salty food (cases, $n=1$ ).

\section{Discussion}

In our study, a higher daily intake of noodles and dumplings was associated with a higher incidence of GC. When stratified by alcohol consumption in participants who were past or current alcohol drinkers, a higher daily intake of noodles and dumplings was associated with a significantly increased incidence of GC. 
Sodium is an essential element for homeostasis and physiological functioning in the body, but high sodium intake has been reported to cause health problems such as obesity [30], high blood pressure [31], cardiovascular disease [32], and GC [9]. Sodium intake is higher when added during cooking or consumed as part of dishes [33]. In addition, salt is not a direct carcinogen, but salty food, including food-derived carcinogens, can increase the incidence of GC [34]. Therefore, it is important to focus on dish groups that contribute to salt intake rather than the salt.

The higher consumption of sodium by Koreans than by inhabitants of other countries may be attributed to the high intake of traditional pickled foods and soup-based diets $[19,20]$. The KNHANES VI data and the outcomes of a study by Song et al. (2013) suggest that soup-based dish groups, such as noodles and dumplings, soups, and stews, contribute the most to sodium intake in Korea [18,20]. However, studies on major dish groups that contribute to sodium intake are rare.

Among the major dish groups with high sodium content, noodles and dumplings are among the most popular foods for Korean adults [35]. In a study on noodle consumption and health problems, a positive association was found between noodle consumption and non-alcoholic fatty liver disease [36], atopic dermatitis [37], cardiovascular disease [38], and GC [39]. In our study, a higher intake of noodles and dumplings increased the incidence of GC. A previous study examined the association between GC and the intake of noodles and bread [39]. In this Chinese case-control study, no association was found between the intake of noodles and bread and the risk of stomach cancer in either men $(\mathrm{OR}=1.1,95 \% \mathrm{CI}=0.9-1.5)$ or women $(\mathrm{OR}=1.2,95 \% \mathrm{CI}=0.8-1.8)$. However, unlike in our study that included noodles and dumplings in one category, they analyzed noodles and bread as part of one category. Therefore, there is a limit to comparing the results of our study with those of previous studies due to the differences in the dish groups. However, several mechanisms may account for the association between the daily intake of noodles and dumplings and the incidence of GC. First, this may be due to the high sodium content in noodles and dumplings. The KNHANES VI (2013-2015) data reported that noodles and dumplings ( $587 \mathrm{mg} /$ day) contributed the most among the dish groups contributing to sodium intake [18]. Farrand et al. (2017) evaluated the sodium content of instant noodles by countries and reported that instant noodles contained too much sodium, especially in China, as the sodium content was $1944 \mathrm{mg} / 100 \mathrm{~g}$ [40]. In Korea, the sodium content of one serving size was $1606 \mathrm{mg} / 120 \mathrm{~g}$ of instant noodles, $956 \mathrm{mg} / 210 \mathrm{~g}$ of buckwheat noodles, $830 \mathrm{mg} / 210 \mathrm{~g}$ of noodles, and $549 \mathrm{mg} / 17 \mathrm{~g}$ of black bean sauce, so the sodium content of the sauce of noodles or the noodles is high [17]. In 2020, the Dietary Reference Intakes for Koreans suggests the adequate intake of sodium (aged 9-64 years) is $1500 \mathrm{mg} /$ day, and the chronic disease risk reduction intake of sodium (aged 9-64 years) is $2300 \mathrm{mg} /$ day [17]. However, the average sodium intake of Koreans was $3512.3 \mathrm{mg} /$ day (aged $\geq 19$ years) [16], which is higher than each standard. Several experimental studies $[6,11]$ have shown that high sodium increases the incidence of GC as it (1) increases the colonization of gastric mucosa by H. pylori infection, (2) damages the mucous cell layer surface, (3) increases the expression of inflammatory mediators such as cyclooxygenase-2 and inducible nitric oxide, and (4) upregulates cagA expression, which leads to inflammation, hypochlorhydria, and enhanced carcinogenesis [11]. Second, this may also be due to the high starch content, unlike other salty foods such as kimchi, soups, and stews. Highly starchy food causes hyperglycemia and hyperinsulinemia, which increases oxidative stress and inflammatory responses [41], and can also lead to gastric carcinogenesis by upregulating glycolysis-related genes (enolase 1) [42]. Ye et al. (2017) reported that in the subgroup analysis, higher carbohydrate intake was significantly associated with increased GC risk in Asian countries [43]. Third, among noodles, instant noodles (ramen) are among the most frequently eaten foods by Koreans, but they have no vegetable content. Koreans usually boil soups and stews with several vegetables (onions, gallic, cabbages, pumpkins, bean sprouts, etc.) and fermented sauces such as soy sauces, soybean paste, or red chili paste. Since vegetables are a good source of various antioxidant 
nutrients, it is well-known that the low consumption of vegetables is associated with an increase in the incidence of GC $[44,45]$. In addition, although the fermented sauces contain a lot of sodium, they also contain nutrients that have anti-cancer effects [15].

The results of previous studies on pickled vegetables, such as kimchi, are inconsistent $[12,22,23]$. In some previous studies, kimchi had a protective effect against GC [12]. These protective effects may be attributed to the anticancer components of kimchi, such as lactic acid bacteria, fiber, and organosulfur compounds [46]. Meanwhile, in some metaanalyses, pickled vegetables were associated with an increased incidence of GC [22,23]. Pickled vegetables have high amounts of sodium as well as the aforementioned healthy nutrients, which may be associated with an increased incidence of GC. In our study, the moderate intake of pickled vegetables showed a tendency to decrease the risk of GC. This result suggests that an adequate amount of kimchi, rather than excessive intake, may help with health problems related to GC. However, this should be further clarified through further research.

In our study, there was no association between the incidence of GC and daily intake of soups and stews. Only one study reported that high-stewed foods, such as soybean paste stew and hot pepper-soybean stew, may increase the risk of GC, although they did not report for the daily intake of stewed foods [21]. In our study, the items included in soups and stews are different from those of previous studies, but we presented daily intakes of soups and stews and included the items of soup and stew that Koreans consume frequently. The effects of soups and stews on GC risk may differ depending on the vegetables in soups and stews, the content of fermented sauce, such as soybean paste, and the actual intake of a person.

Smoking and alcohol consumption are well-known behavioral risk factors for GC [3]. Additionally, these behavioral factors are associated with unhealthy dietary patterns [24]. Lampuré et al. (2015) reported that smokers or alcohol drinkers prefer salty food [20], and smokers have a low intake of fruits and dairy products and a high intake of fast food [21]. Smoking and alcohol consumption can act as carcinogenic factors [27], but when they are combined with unhealthy dietary habits, it is thought that their effect on GC incidence may be worse. Especially, one of the mechanisms of alcohol consumption that affects GC is the production of inflammatory markers (i.e., prostaglandins and lipid peroxidation) and the generation of oxidative stress substances such as oxygen radical species [2]. Since this mechanism is a reaction that increases in the body even with the intake of high starchy foods [41], it may have a synergistic effect on the incidence of GC in a subject with two factors such as increased noodle consumption and alcohol consumption. In the present study, when smoking or alcohol drinking status was analyzed without stratification, statistical significance could not be confirmed in the participants who had ever smoked and drunk alcohol after adjusting for confounding factors. However, when stratified by alcohol drinking or smoking status, we found that a higher intake of noodles and dumplings significantly increased the risk of GC $(\mathrm{OR}=2.00,95 \% \mathrm{CI}=1.12-3.56)$ in participants who had ever drunk alcohol and showed a tendency of increased risk of GC $(\mathrm{OR}=1.68,95 \% \mathrm{CI}=0.92-3.05)$ in participants who had ever smoked. From these results, we could confirm that the association between the intake of noodles and dumplings and GC increased in participants who had ever drunk alcohol or smoked. In addition, when stratified by family history of GC or H. pylori infection, we found that a higher intake of noodles and dumplings showed a tendency of increased risk of GC in participants with a family history of GC or with positive H. pylori infection (Table S1). Therefore, efforts to reduce excessive intake of noodles and dumplings in participants with GC risk factors are considered necessary.

In addition, several studies have reported an association between salty food preference and GC [7,47]. Kim et al. (2009) reported that the preference for a salty taste is related to the intake of salty food and its frequency [48]. We also confirmed that the risk of GC showed an increased tendency when salty taste was preferred (Table 5). Since preference 
for salty taste is related to the intake of salty foods, participants who prefer a salty taste need to receive dietary education and diet management for the prevention of GC.

This study has several strengths. It was conducted based on the ranking of major dish groups that contribute to sodium intake in Koreans, and it confirmed the association between GC and the intake of noodles and dumplings, which has not been reported in other studies. In addition, to avoid information bias, interviews of all subjects were conducted without disclosing the disease status after endoscopic examination. In addition, to avoid misclassification bias, controls recruited from the same hospital during the same period were confirmed to have no gastric problems through gastroscopy. This study also has limitations. In our study, the cases were recruited from only two hospitals, the controls were also recruited from the patients who visited the hospital, and they may be less representative of the general population. In addition, the sample for the analysis was small because some cases and controls could not be matched by age, sex, or hospital. There was also a slight difference in the content of the FFQ survey for the first and second stages, and there may have been unintentional misclassification. In addition, we adjusted for various confounding factors in the statistical model; however, there may have been residual confounding effects. Moreover, in our study, the $H$. pylori infection rate was found to be lower in cases than in the controls. This might be due to the fact that $H$. pylori detection rates can decrease with the progression of gastric atrophy and intestinal metaplasia [49,50]. Regarding family history of GC, we previously identified a significant increase in the incidence of GC in subjects with a family history of GC in our previous case-control study (316 pairs) (OR: 1.69, 95\% CI: 1.04-2.74) [51]. However, in this study, as the number of subjects was rematched according to the study purpose and reduced to 307 pairs, the significance between the incidence of GC in subjects with a family history of GC disappeared. This is probably due to the fact that the sample size was too small detect the minor contributors to GC.

\section{Conclusions}

Our study showed that the risk of GC increased with the high intake of noodles and dumplings among Koreans, especially in participants who were past or current drinkers. Therefore, in order to prevent and reduce GC, we suggest that Koreans need to reduce their broth intake when eating noodles, make practical efforts to consume as little salt as possible when eating food, and reduce the salt content of noodles themselves as a policy.

Supplementary Materials: The following are available online at https:/ / www.mdpi.com/article/10 $.3390 /$ nu13041365/s1, Table S1: Association gastric cancer and intakes of noodles and dumplings according to family history of gastric cancer or H. pylori infection.

Author Contributions: Conceptualization, J.-H.K. and H.-J.K.; formal analysis, J.-H.K. writingoriginal draft preparation, J.-H.K.; writing -review and editing, J.-H.K. and H.-J.K.; investigation, C.-S.E., D.-S.H., Y.-S.K., K.-S.S., B.-Y.C., and H.-J.K.; visualization, J.-H.K.; supervision, H.-J.K. and B.-Y.C. All authors have read and agreed to the published version of the manuscript.

Funding: This research was supported by the Basic Science Research Program through the National Research Foundation of Korea (NRF), funded by the Ministry of Education (Grant Number 2020R111A3A04036989).

Institutional Review Board Statement: The study protocol was approved by the Institutional Review Board of Hanyang University Medical Center (IRB no.2003-4).

Informed Consent Statement: Informed consent was obtained from all subjects involved in the study.

Data Availability Statement: The data presented in this study are available on request from the corresponding author. The data are not publicly available because of the privacy of the subjects.

Conflicts of Interest: The authors declare no conflict of interest. 


\section{References}

1. Sung, H.; Ferlay, J.; Siegel, R.L.; Laversanne, M.; Soerjomataram, I.; Jemal, A.; Bray, F. Global cancer statistics 2020: GLOBOCAN estimates of incidence and mortality worldwide for 36 cancers in 185 countries. CA Cancer J. Clin. 2021. [CrossRef] [PubMed]

2. World Cancer Research Fund International; American Institute for Cancer Research. Stomach Cancer Statistics. Available online: https:/ / www.wcrf.org/dietandcancer/cancer-trends/stomach-cancer-statistics (accessed on 27 March 2021).

3. Statistics KOREA. Cancer Incidence and Death Status. Available online: https://www.index.go.kr/potal/main/EachDtlPageDetail. do?idx_cd=2770 (accessed on 18 February 2021).

4. Yusefi, A.R.; Bagheri Lankarani, K.; Bastani, P.; Radinmanesh, M.; Kavosi, Z. Risk Factors for Gastric Cancer: A Systematic Review. Asian Pac. J. Cancer Prev. 2018, 19, 591-603. [PubMed]

5. World Cancer Research Fund International; American Institute for Cancer Research. Diet, Nutrition, Physical Activity, and Stomach Cancer; World Cancer Research Fund International: London, UK, 2018.

6. D'Elia, L.; Galletti, F.; Strazzullo, P. Dietary salt intake and risk of gastric cancer. Cancer Treat. Res. 2014, 159, 83-95. [PubMed]

7. Umesawa, M.; Iso, H.; Fujino, Y.; Kikuchi, S.; Tamakoshi, A. Salty Food Preference and Intake and Risk of Gastric Cancer: The JACC Study. J. Epidemiol. 2016, 26, 92-97. [CrossRef]

8. Lin, S.H.; Li, Y.H.; Leung, K.; Huang, C.Y.; Wang, X.R. Salt processed food and gastric cancer in a Chinese population. Asian Pac. J. Cancer Prev. 2014, 15, 5293-5298. [CrossRef]

9. D'Elia, L.; Rossi, G.; Ippolito, R.; Cappuccio, F.P.; Strazzullo, P. Habitual salt intake and risk of gastric cancer: A meta-analysis of prospective studies. Clin. Nutr. 2012, 31, 489-498. [CrossRef]

10. Strumylaite, L.; Zickute, J.; Dudzevicius, J.; Dregval, L. Salt-preserved foods and risk of gastric cancer. Medicina 2006, 42, 164-170.

11. Gaddy, J.A.; Radin, J.N.; Loh, J.T.; Zhang, F.; Washington, M.K.; Peek, R.M., Jr.; Algood, H.M.; Cover, T.L. High dietary salt intake exacerbates Helicobacter pylori-induced gastric carcinogenesis. Infect. Immun. 2013, 81, 2258-2267. [CrossRef]

12. Kim, H.J.; Chang, W.K.; Kim, M.K.; Lee, S.S.; Choi, B.Y. Dietary factors and gastric cancer in Korea: A case-control study. Int. J. Cancer 2002, 97, 531-535. [CrossRef]

13. Takachi, R.; Inoue, M.; Shimazu, T.; Sasazuki, S.; Ishihara, J.; Sawada, N.; Yamaji, T.; Iwasaki, M.; Iso, H.; Tsubono, Y.; et al. Consumption of sodium and salted foods in relation to cancer and cardiovascular disease: The Japan Public Health Center-based Prospective Study. Am. J. Clin. Nutr. 2010, 91, 456-464.

14. Sjödahl, K.; Jia, C.; Vatten, L.; Nilsen, T.; Hveem, K.; Lagergren, J. Salt and gastric adenocarcinoma: A population-based cohort study in Norway. Cancer Epidemiol. Biomark. Prev. 2008, 17, 1997-2001. [CrossRef]

15. Kim, J.S.; Kim, J.H.; Palaniyandi, S.A.; Lee, C.C.; You, J.W.; Yang, H.; Yoon Park, J.H.; Yang, S.H.; Lee, K.W. Yak-Kong Soybean (Glycine max) Fermented by a Novel Pediococcus pentosaceus Inhibits the Oxidative Stress-Induced Monocyte-Endothelial Cell Adhesion. Nutrients 2019, 11, 1380. [CrossRef]

16. Korea Centers for Disease Control and Prevention. Korea Health Statistics 2019: Korea National Health and Nutrition Examination Survey (KNHANES VIII-1); Korea Centers for Disease Control and Prevention: Cheongju, Korea, 2020; pp. 124-126.

17. The Korean Nutrition Society. Dietary Reference Intakes for Koreans 2020; Ministry of Health and Welfare: Sejong, Korea, 2020; pp. 69-88.

18. Yun, S.; Oh, K. Dietary and Nutritional Status of Koreans Based on the Health Plan. 2020 Nutrition Indicators; Division of Health and Nutrition Survey, Center for Disease Control and Prevention: Chungbuk, Korea, 2018.

19. Yon, M.; Lee, Y.; Kim, D.; Lee, J.; Koh, E.; Nam, E.; Shin, H.J.; Kang, B.; Kim, J.W.; Heo, S.; et al. Major Sources of Sodium Intake of the Korean Population at Prepared Dish Level-Based on the KNHANES 2008 \& 2009. Korean J. Community Nutr. 2011, 16, $473-487$.

20. Song, D.Y.; Park, J.E.; Shim, J.E.; Lee, J.E. Trends in the major dish groups and food groups contributing to sodium intake in the Korea National Health and Nutrition Examination Survey 1998-2010. J. Nutr. Health 2013, 46, 72-85. [CrossRef]

21. Lee, J.K.; Park, B.J.; Yoo, K.Y.; Ahn, Y.O. Dietary factors and stomach cancer: A case-control study in Korea. Int. J. Epidemiol. 1995, 24, 33-41. [CrossRef]

22. Kim, H.J.; Lim, S.Y.; Lee, J.S.; Park, S.; Shin, A.; Choi, B.Y.; Shimazu, T.; Inoue, M.; Tsugane, S.; Kim, J. Fresh and pickled vegetable consumption and gastric cancer in Japanese and Korean populations: A meta-analysis of observational studies. Cancer Sci. 2010, 101, 508-516. [CrossRef]

23. Woo, H.D.; Park, S.; Oh, K.; Kim, H.J.; Shin, H.R.; Moon, H.K.; Kim, J. Diet and cancer risk in the Korean population: A meta-analysis. Asian Pac. J. Cancer Prev. 2014, 15, 8509-8519. [CrossRef]

24. Cho, E.R.; Shin, A.; Lim, S.Y.; Kim, J. Dietary patterns and their associations with health behaviours in Korea. Public Health Nutr. 2011, 14, 356-364. [CrossRef]

25. Lampuré, A.; Schlich, P.; Deglaire, A.; Castetbon, K.; Péneau, S.; Hercberg, S.; Méjean, C. Sociodemographic, psychological, and lifestyle characteristics are associated with a liking for salty and sweet tastes in French adults. J. Nutr. 2015, 145, 587-594. [CrossRef]

26. Lee, B.; Yi, Y. Smoking, Physical Activity, and Eating Habits Among Adolescents. West. J. Nurs Res. 2016, 38, 27-42. [CrossRef]

27. Seitz, H.K.; Cho, C.H. Contribution of alcohol and tobacco use in gastrointestinal cancer development. Methods Mol. Biol. 2009, 472, 217-241. [PubMed]

28. Washington, M.K.; Goldberg, R.M.; Chang, G.J.; Limburg, P.; Lam, A.K.; Salto-Tellez, M.; Arends, M.J.; Nagtegaal, I.D.; Klimstra, D.S.; Rugge, M.; et al. Diagnosis of digestive system tumours. Int. J. Cancer 2021, 148, 1040-1050. [CrossRef] [PubMed] 
29. The Korean Nutrition Society. Foods and Nutrients Database of Computer Aided Nutritional Analysis Program, Version 2.0; The Korean Nutrition Information Center: Seoul, Korea, 2003.

30. Zhang, X.; Wang, J.; Li, J.; Yu, Y.; Song, Y. A positive association between dietary sodium intake and obesity and central obesity: Results from the National Health and Nutrition Examination Survey 1999-2006. Nutr. Res. 2018, 55, 33-44. [CrossRef] [PubMed]

31. Grillo, A.; Salvi, L.; Coruzzi, P.; Salvi, P.; Parati, G. Sodium Intake and Hypertension. Nutrients 2019, 11, 1970. [CrossRef] [PubMed]

32. Mente, A.; O’Donnell, M.; Rangarajan, S.; Dagenais, G.; Lear, S.; McQueen, M.; Diaz, R.; Avezum, A.; Lopez-Jaramillo, P.; Lanas, F.; et al. Associations of urinary sodium excretion with cardiovascular events in individuals with and without hypertension: A pooled analysis of data from four studies. Lancet 2016, 388, 465-475. [CrossRef]

33. Son, S.M.; Huh, G.Y.; Lee, H.S. Development and evaluation of validity of dish frequency questionnaire (DFQ) and short DFQ using Na index for estimation of habitual sodium intake. Korean J. Community Nutr. 2005, 10, 677-692.

34. Knekt, P.; Järvinen, R.; Dich, J.; Hakulinen, T. Risk of colorectal and other gastro-intestinal cancers after exposure to nitrate, nitrite and N-nitroso compounds: A follow-up study. Int. J. Cancer 1999, 80, 852-856. [CrossRef]

35. Han, G. Consumption Status of Commercial Staple Food in Korean Adults: Data from 2010 2014 Korea National Health and Nutrition Examination Survey. CSHR 2017, 23, 54-66.

36. Tajima, R.; Kimura, T.; Enomoto, A.; Yanoshita, K.; Saito, A.; Kobayashi, S.; Masuda, K.; Iida, K. Association between rice, bread, and noodle intake and the prevalence of non-alcoholic fatty liver disease in Japanese middle-aged men and women. Clin. Nutr. 2017, 36, 1601-1608. [CrossRef]

37. Park, S.; Choi, H.S.; Bae, J.H. Instant noodles, processed food intake, and dietary pattern are associated with atopic dermatitis in an adult population (KNHANES 2009-2011). Asia Pac. J. Clin. Nutr. 2016, 25, 602-613.

38. Shin, H.J.; Cho, E.; Lee, H.J.; Fung, T.T.; Rimm, E.; Rosner, B.; Manson, J.E.; Wheelan, K.; Hu, F.B. Instant noodle intake and dietary patterns are associated with distinct cardiometabolic risk factors in Korea. J. Nutr. 2014, 144, 1247-1255. [CrossRef]

39. Ji, B.T.; Chow, W.H.; Yang, G.; McLaughlin, J.K.; Zheng, W.; Shu, X.O.; Jin, F.; Gao, R.N.; Gao, Y.T.; Fraumeni, J.F., Jr. Dietary habits and stomach cancer in Shanghai, China. Int. J. Cancer 1998, 76, 659-664. [CrossRef]

40. Farrand, C.; Charlton, K.; Crino, M.; Santos, J.; Rodriguez-Fernandez, R.; Ni Mhurchu, C.; Webster, J. Know Your Noodles! Assessing Variations in Sodium Content of Instant Noodles across Countries. Nutrients 2017, 9, 612. [CrossRef]

41. Marimuthu, S.P.; Vijayaragavan, P.; Moysich, K.B.; Jayaprakash, V. Diabetes mellitus and gastric carcinoma: Is there an association? J. Carcinog. 2011, 10, 30.

42. Xu, X.; Chen, B.; Zhu, S.; Zhang, J.; He, X.; Cao, G.; Chen, B. Hyperglycemia promotes Snail-induced epithelial-mesenchymal transition of gastric cancer via activating ENO1 expression. Cancer Cell Int. 2019, 19, 344. [CrossRef]

43. Ye, Y.; Wu, Y.; Xu, J.; Ding, K.; Shan, X.; Xia, D. Association between dietary carbohydrate intake, glycemic index and glycemic load, and risk of gastric cancer. Eur. J. Nutr. 2017, 56, 1169-1177. [CrossRef]

44. Ferro, A.; Costa, A.R.; Morais, S.; Bertuccio, P.; Rota, M.; Pelucchi, C.; Hu, J.; Johnson, K.C.; Zhang, Z.F.; Palli, D.; et al. Fruits and vegetables intake and gastric cancer risk: A pooled analysis within the Stomach cancer Pooling Project. Int. J. Cancer 2020, 147, 3090-3101. [CrossRef]

45. Kim, J.H.; Lee, J.; Choi, I.J.; Kim, Y.I.; Kwon, O.; Kim, H.; Kim, J. Dietary Carotenoids Intake and the Risk of Gastric Cancer: A Case-Control Study in Korea. Nutrients 2018, 10, 1031. [CrossRef]

46. Kwak, S.H.; Cho, Y.M.; Noh, G.M.; Om, A.S. Cancer Preventive Potential of Kimchi Lactic Acid Bacteria (Weissella cibaria, Lactobacillus plantarum). J. Cancer Prev. 2014, 19, 253-258. [CrossRef]

47. Kim, J.; Park, S.; Nam, B.H. Gastric cancer and salt preference: A population-based cohort study in Korea. Am. J. Clin. Nutr 2010, 91, 1289-1293. [CrossRef]

48. Kim, G.H.; Lee, H.M. Frequent consumption of certain fast foods may be associated with an enhanced preference for salt taste. J. Hum. Nutr. Diet. 2009, 22, 475-480. [CrossRef] [PubMed]

49. Yoon, H.; Kim, N.; Lee, H.S.; Shin, C.M.; Park, Y.S.; Lee, D.H.; Jung, H.C.; Song, I.S. Helicobacter pylori-negative gastric cancer in South Korea: Incidence and clinicopathologic characteristics. Helicobacter 2011, 16, 382-388. [CrossRef] [PubMed]

50. Kang, H.Y.; Kim, N.; Park, Y.S.; Hwang, J.H.; Kim, J.W.; Jeong, S.H.; Lee, D.H.; Jung, H.C.; Song, I.S. Progression of atrophic gastritis and intestinal metaplasia drives Helicobacter pylori out of the gastric mucosa. Dig. Dis.Sci. 2006, 51, 2310-2315. [CrossRef] [PubMed]

51. Kim, M.H.; Kim, S.A.; Park, C.H.; Eun, C.S.; Han, D.S.; Kim, Y.S.; Song, K.S.; Choi, B.Y.; Kim, H.J. Alcohol consumption and gastric cancer risk in Korea: A case-control study. Nutr. Res. Pract. 2019, 13, 425-433. [CrossRef] 